\title{
An Apportionment of Arsenic and Iron Contamination of Tube-well Groundwater with Possible Health Risk in Bangladesh
}

\author{
Ram Proshad ${ }^{1, *}$, Tapos Kormoker ${ }^{2}$, Md. Saiful Islam ${ }^{1}$, Bidhan Chandra Saha $^{3}$, \\ Md. Ripon Hossain ${ }^{4}$, Mahamud Hasan Prince ${ }^{5}$, Mohammed Mahmud Khan ${ }^{6}$ \\ ${ }^{1}$ Department of Soil Science, Patuakhali Science and Technology University, Dumki, Patuakhali, Bangladesh \\ ${ }^{2}$ Department of Emergency Management, Patuakhali Science and Technology University, Dumki, Patuakhali, Bangladesh \\ ${ }^{3}$ Department of Agriculture Studies, Muktizoddha Memorial College, Mohipur Kalapara, Patuakhali, Bangladesh \\ ${ }^{4}$ Department of Entomology, Patuakhali Science and Technology University, Dumki, Patuakhali, Bangladesh \\ ${ }^{5}$ Department of Horticulture, Patuakhali Science and Technology University, Dumki, Patuakhali, Bangladesh \\ ${ }^{6}$ Department of Public Health Engineering (DPHE), Government of the People's Republic of Bangladesh \\ *Corresponding author: ramproshadpstu03470@gmail.com
}

\begin{abstract}
Underground tube-well water is one of the most important sources of pure drinking water in the world. Drinking water contamination with heavy metals (iron and arsenic) is a burning question nowadays for public health and also environmental perspectives. Our present task is for determination of iron and arsenic concentration in ground tube-well with possible health risk in Bangladesh. The water samples were collected from Tangail district of Bangladesh during January 2017. Iron and arsenic concentration were analyzed by using Atomic Absorption Spectrophotometer. Iron concentration ranged from 4.483 to $20.698 \mathrm{mg} / \mathrm{l}$ where arsenic concentration was obtained from $<0.001$ to $0.01969 \mathrm{mg} / \mathrm{l}$ in the studied samples. Arsenic concentration for most of the samples and all iron samples were higher than the maximum permissible level of World Health Organization due to drinking these water. Iron is a heavy metal may cause serious health risk to study area people. In Bangladesh, permissible limit of iron is $0.3-1.0 \mathrm{mg} / \mathrm{l}$, whereas WHO standard level is $0.3 \mathrm{mg} / \mathrm{l}$. All the samples were exceeded the standard levels of iron. A range of 20 to 60 times higher iron concentration reported than permissible limits in tube-well water of the study area. These higher iron concentrations found in the study area may be harmful to those people who are consuming the water from these sources on regular basis and they may pose a high health risk. Thus, to overcome this problem, the consumers should not drink groundwater containing higher amounts of iron, and they should find other sources or replace the tube-well or treat the water for drinking and other domestic and household purposes.
\end{abstract}

Keywords: arsenic, iron, tube-well water, health risk, Bangladesh

Cite This Article: Ram Proshad, Tapos Kormoker, Md. Saiful Islam, Bidhan Chandra Saha, Md. Ripon Hossain, Mahamud Hasan Prince, Mohammed Mahmud Khan, "An Apportionment of Arsenic and Iron Contamination of Tube-well Groundwater with Possible Health Risk in Bangladesh." Journal of Environment Pollution and Human Health, vol. 5, no. 3 (2017): 117-123. doi: 10.12691/jephh-5-3-7.

\section{Introduction}

Water is the foremost constituent of the fluids of livings and is decisive for all known forms of life. No other planet in the universe other than earth is a livable place for humans and other living things because of the non-existence of water. Groundwater act as an important component of natural resources and plays a significant role to serve as many purposes as drinking, irrigation, and other domestic usages [1]. If groundwater becomes contaminated by organic and inorganic toxic materials especially heavy metals that develop a major problem for both the public health and the environment. Globally groundwater is estimated to provide approximately $50 \%$ of current potable water supplies, $40 \%$ of the water demand of self-supplied industry and $20 \%$ of water use in irrigation. Pressures on groundwater resources over the next 25 years in Asia will come from demographic increases, agricultural practices and increasing water demand per capita, coupled with increased urban areas, industrial activity and energy demand [2]. Groundwater contamination in Bangladesh is reported to be the biggest issue in the world nowadays [3]. Bangladesh is a developing country facing major problem of water pollution due to leaching of harmful materials and chemicals from anthropogenic sources, such as the promiscuous application of pesticides and fertilizers, excess disposal of waste materials, etc. [4]. Among these groundwater contaminations, iron and arsenic are the most harmful which are present trace in amount, but have significant effects on drinking water and causes harmful impacts on human health in developing countries of South East Asia [5]. In developing countries, about $80 \%$ of the diseases are related to contaminated water and the resulting death 10 million per year [6]. Arsenic is a heavy 
metal generally occurs in rocks and soil. Inorganic arsenic has assumed as a carcinogenic agent according to the Department of Health and Human Services (DHHS), Environmental Protection Agency (EPA) and World Health Organization (WHO) which have the potentiality to cause cancer in humans $[7,8]$. Tube-well water contaminated by arsenic (As) in 61 districts of Bangladesh [9]. About more than 20 million people drink water exceeding the national standard for arsenic levels [10]. Different studies have reported that inorganic arsenic has the risk of liver cancer, lung cancer, bladder cancer, skin cancer, prostate cancer and kidney cancer $[3,5,8]$. Arsenic has a non-carcinogenic effect due to its contamination in groundwater includes stomach pain, thickening, and discoloration of the skin, diarrhea, nausea, partial paralysis, vomiting numbness in hands and feet, blindness etc. [8]. The toxicological study indicates that organic arsenic is of less toxic than inorganic arsenic because organic arsenic is more rapidly excreted than inorganic but trivalent inorganic arsenic is found more dangerous than pentavalent due to less excretion ability in human metabolism [11]. In groundwater, arsenic is found as an inorganic form so therefore this poses a great hazard to human health. It is very much important to monitor the concentration of arsenic and other physicochemical factors in groundwater of the corresponding area to have solid research findings of water pollution. Arsenic contamination in groundwater and its risk assessment to the human health from various countries of the world has also been reported in literature including India, China, USA, Mexico, Canada, Argentina, Mongolia, Vietnam, Romania, Germany, and Thailand [12]. Similarly, Bangladesh is also facing serious arsenic pollution in its groundwater in various places. In Bangladesh, arsenic contamination of water in tube-wells was confirmed in 1993 in the Nawabganj district [13]. Further testing was done in the following years; this included investigations by the Department of Occupational and Environmental Health of the National Institute of Preventive and Social Medicine. Results from various laboratories were collated in a WHO country situation report in 1996. The institutions that provided results included the Jadavpur University in Calcutta, India, the Bangladesh Atomic Energy Commission, the Department of Public Health Engineering's laboratories in the Khulna and Rajshahi districts, and the National Institute of Preventive and Social Medicine in Dhaka. Altogether, 400 measurements were presented in their port, although contamination in some wells was measured by more than one laboratory. In about half of the measurements, concentrations were above $50 \mathrm{mg} / \mathrm{l}$, which is clearly in excess of the maximum level recommended by WHO of $10 \mathrm{mg} / 1$ [14] and greater than the maximum level of $50 \mathrm{mg} / 1$ permitted in Bangladesh [15]. The recent statistics on arsenic contamination indicate that 59 out of 64 districts of Bangladesh have been affected by arsenic contamination. Approximately, arsenic has contaminated the groundwater in $85 \%$ of the total area of Bangladesh and about 75 million people are at risk. Approximately, arsenic has contaminated the groundwater in $85 \%$ of the total area of Bangladesh and about 75 million people are at risk10. It has been estimated that at least 1.2 million people are exposed to arsenic poisoning. The reported number of patients seriously affected by arsenic in drinking water has now risen to 8500 [16]. Groundwater contamination by iron is one of the burning questions as groundwater is an important resource for livelihoods and food security of billions of people. Not only arsenic (As) but also iron $(\mathrm{Fe})$ contamination in groundwater is now a vital problem in Bangladesh. Iron is the second most abundant metal in the earth's crust, of which it accounts for about 5\%. Elemental iron is rarely found in nature, as the $\mathrm{Fe}$ ions $\mathrm{Fe}+2$ and $\mathrm{Fe}+3$ readily combine with oxygen- and sulfur-containing compounds to form oxides, hydroxides, carbonates, and sulfides. It is most commonly found in nature in the form of its oxides [17]. A large number of sources and causes can modify groundwater quality, ranging from septic tanks to irrigated agriculture $[18,19]$. Groundwater in Bangladesh, except in some places, is available at a shallow depth. Groundwater levels are at or near ground level during the period August to October and lowest in April to May. The concentration of iron content in the water environment is about $0.27 \mathrm{ppm}$ in spring and $0.67 \mathrm{ppm}$ in the summer season. In several areas of Bangladesh, groundwater withdrawals are causing a large iron contamination in groundwater levels during the dry season [20]. As millions of people of Bangladesh rely on groundwater sources for their daily domestic and other purposes, the assessment of groundwater quality is one of the most important tasks. The results of such investigations can minimize different health related problems and can ensure a healthy life with safe drinking water sources. Thus, the evaluation of arsenic and iron in groundwater and correlation with other chemical properties ( $\mathrm{pH}$ and electrical conductivity) is the need of the time. It becomes more important to investigate the possible sources of arsenic and iron pollution by using multivariate techniques and possible health risk (noncarcinogenic and carcinogenic) due to drinking of contaminated tube-well water. As well as examine the effect of poisons in different sampling sites, in view to find out the information about similarities and dissimilarities among the different sampling sites, according to arsenic and iron contamination levels.

\section{Materials and Methods}

\subsection{Study Area and Sampling}

The fifteen different sampling sites (tube-well water) were selected for this study in Gopalpur, Tangail district, Bangladesh (Figure 1). The area of the study area is 193.37 $\mathrm{km}^{2}$ and located at the center point in Bangladesh. Gopalpur of Tangail district is one of the most densely polluted areas in Bangladesh where the density of population is $1,100 / \mathrm{km} 2$ (2011 census). The study area is situated between $24.55^{\circ} \mathrm{N}$ to $89.91^{\circ} \mathrm{E}$. During January, 2017 tube-well water samples were collected. The present situation of the tube-well presented in Figure 2. All the samples were collected in $250 \mathrm{ml}$ plastic bottles with a screw cap and well washed before collection to make sure that it is free from any undesirable materials and contaminations. The following processes were followed to wash the bottles, collect and preserve the samples: a) the bottles were washed thoroughly with tap water, then 
rinsed with distilled water and hydrochloric acid $(\mathrm{HCl}) ; \mathrm{b})$ the bottles were putted in the oven and dried at $30^{\circ} \mathrm{C}$ for 2 hours; c) the bottles were completely filled with sample water to the brim; d) during the filling of sample water to bottles, they were maintained continuously till it was completely filled with sample water and thereby minimize air oxidation; e) then the bottles were tightly screwed and fixed up with cello tape; f) from each sample, $50 \%$ was preserved by adding $2-3 \mathrm{ml}$ of HCI $(0.1 \mathrm{M})$ to control the changing of chemical characteristics of water, then the samples were kept in the laboratory. Finally the samples were brought to central laboratory of Patuakhali Science and Technology University, Bangladesh for determination of chemical properties ( $\mathrm{pH}$ and EC) and Analytical Research Laboratory of the Department of Public Health Engineering (DPHE) Barisal Zonal Lab, Barisal, Bangladesh to test the metal concentration (As and $\mathrm{Fe}$ ); vii) all the samples were stored in dark place as far as possible during the sampling and transportation to the laboratory. The samples were preserved again with conc. Nitric acid (HNO3) at the rate of $5 \mathrm{ml}$ in each $250 \mathrm{ml}$ bottle [21].

\subsection{Sample analysis}

To analyze the chemical properties of water, various standard methods were followed and a number of sophisticated instruments were used. A digital Global Positioning System (GPS) software (GNSS viewer) was used to measure the position of the aquifers of water samples. A digital $\mathrm{pH}$ meter and electrical conductivity meter were used to determine $\mathrm{pH}$ and $\mathrm{EC}$ of the collected tube-well water samples. Atomic Absorption Spectrophotometer (AAS) was used to analyze the arsenic and iron in the water samples respectively.

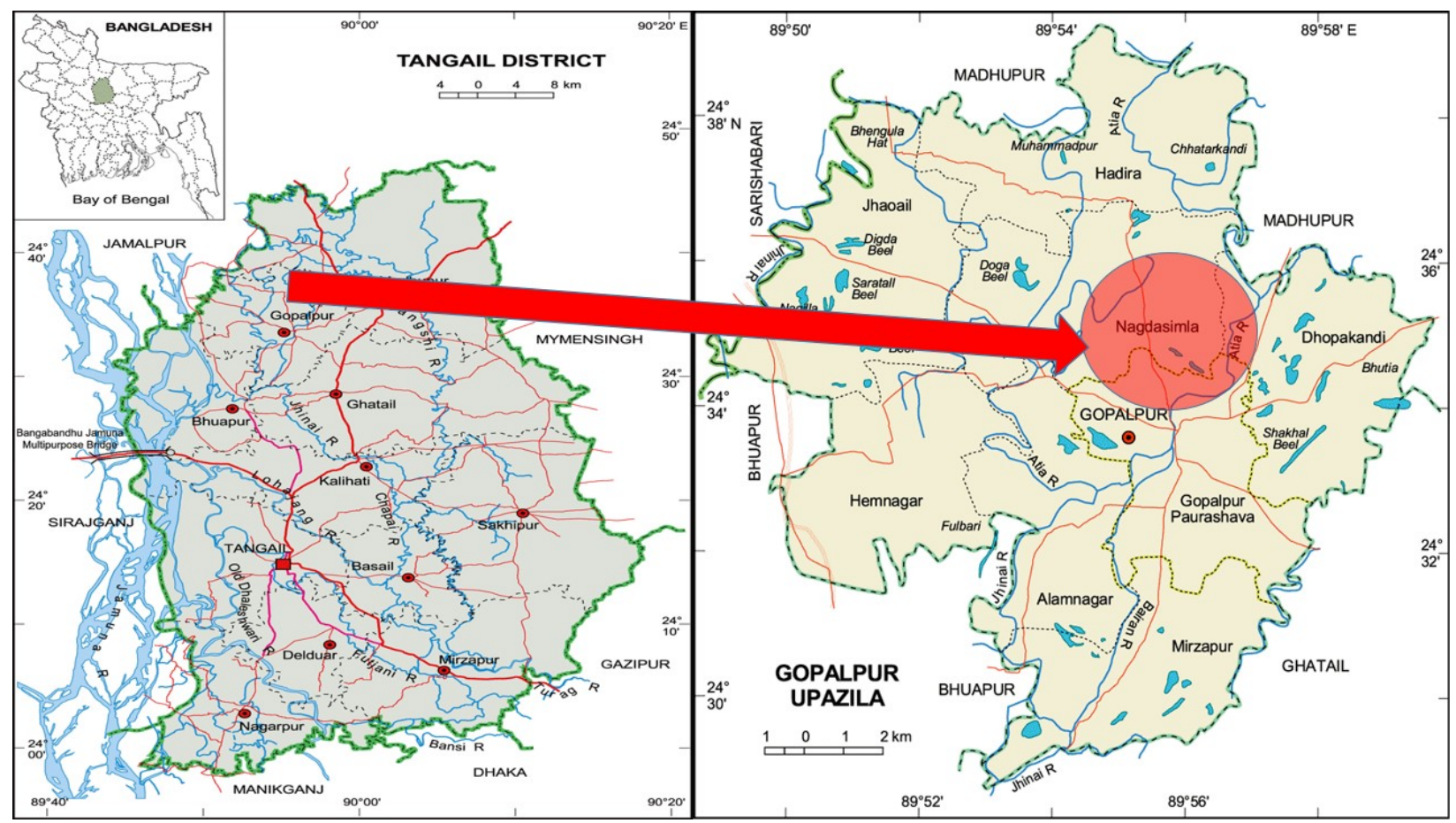

Figure 1. Map showing the sampling site of tube-well water of Tangail district, Bangladesh
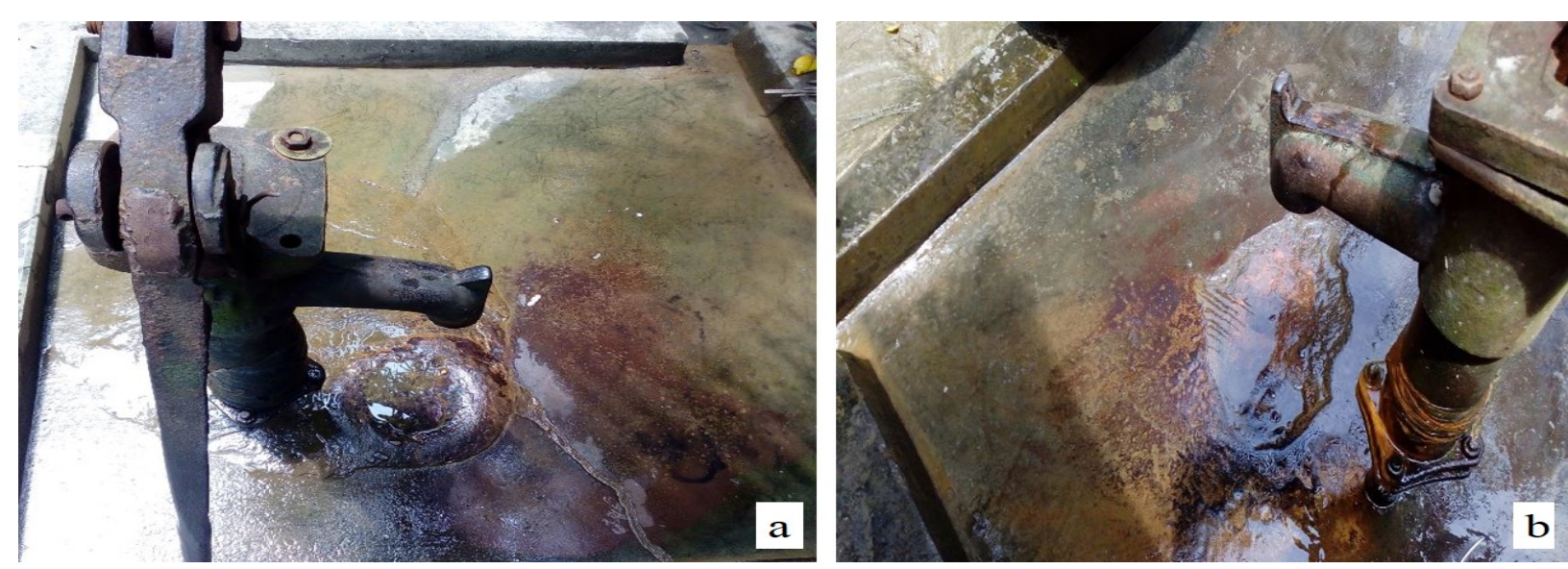

Figure 2. Present situation of tube-well floor in Tangail district, Bangladesh (yellowish color of generally indicated the presence of iron) 


\subsection{Arsenic Risk Assessment}

Display arsenic risk factor has been calculated for non-carcinogenic exposure, as hazard quotient (HQ), can be calculated as

$$
\mathrm{HQ}=\mathrm{ADD} / \mathrm{RfD}
$$

Where, RfD is the oral toxicity reference value for As equaling to $3.04 \mathrm{E}-04 \mathrm{mg} / \mathrm{l} /$ day and $\mathrm{ADD}$ is the average daily intake dose ( $\mathrm{mg} / \mathrm{l} /$ day).

$$
\mathrm{ADD}=\{(\text { Cwater } \times \mathrm{IR} \text { water }) \times \mathrm{EF} \times \mathrm{ED}\} /(\mathrm{AT} \times \mathrm{BW})(2)
$$

Where, Cwater indicates the arsenic concentration in water $(\mathrm{mg} / \mathrm{l})$, IRwater the water ingestion rate (1/day), EF the exposure frequency (days/year), ED the exposure duration (years), AT indicates the arsenic concentration in water (mg/l), AT the average age time (days), and BW is the body weight $(\mathrm{kg})$. If the calculated HQ is $<1$, then no adverse health effects are expected as a result of exposure. If the HQ was $>1$, then adverse health effects are possible [22]. Body weights were obtained by weighing each individual on a body weight scale. The water ingestion rate was 2-3 1 (average 2.51 ) of water per day.

\subsection{Carcinogenic Risk Assessment}

The target carcinogenic risks derived from the intake of arsenic was calculated using the equation provided in USEPA Region III Risk-Based Concentration Table [23]. The carcinogenic risk factor is the probability of an incidence of cancer from chemical exposure and can be computed as:

$$
\mathrm{R}=1-\exp [(\mathrm{SF} \times \mathrm{ADD})]
$$

Where, SF is the oral slope factor. Toxicity data for threshold and non-threshold effects from arsenic exposure are available from the USEPA database, Integrated Risk Information System [23]. The oral slope factor (SF) for arsenic is $1.5 \mathrm{mg} / \mathrm{l} / \mathrm{day}$. In order to estimate carcinogenic risk, it was supposed that people are dependent on groundwater in Bangladesh for their drinking and other domestic purposes. In understudied areas of Bangladesh, the rural population mostly relies on underground water resources.

\subsection{Statistical Analysis}

The data were statistically analyzed using the statistical package, SPSS 20.0 (SPSS, USA). Other calculations were performed by Microsoft Excel 2013.

\section{Results and Discussion}

All the tube-well water samples were collected with very carefully. There were no color and odor of water during collection and it indicated the purity of water. The tube-well water sampling location with chemical properties, arsenic and iron concentration were shown in Table 1. The $\mathrm{pH}$ is one of the most important parameters to test the water quality and it is also a useful test for interpretation of water chemistry. The $\mathrm{pH}$ of tube-well water samples was found neutral and it was within the WHO recommended values. Electrical conductivity (EC) value of the tube-well water was non-saline $(0-2 \mathrm{dS} / \mathrm{m})$ for all sampling sites which mean the salinity effect is negligible.

Data obtained from analysis indicated that level of arsenic concentration ranged from $<0.001$ to $0.01969 \mathrm{mg} / 1$ in the studied vicinity tube-well water (Table 1 and Figure 3). It can be said that arsenic concentration for most of the water samples comparatively higher than WHO recommended limit $(10 \mu \mathrm{g} / \mathrm{l})$. The comparison study of arsenic in groundwater with World Health Organization limit $(10 \mu \mathrm{g} / \mathrm{l})$ is indicated that about $94 \%$ samples were higher and it was contaminated by arsenic. Arsenic concentration above than WHO recommended guidelines and therefore these are chemically unfit for human consumption of study area. Intermittent incidents of arsenic contamination in groundwater can arise both naturally and industrially. The natural occurrence of arsenic in groundwater is directly related to the arsenic complexes present in soils. Arsenic can liberate from these complexes under some circumstances. Since arsenic in soils is highly mobile, once it is liberated, it results in possible groundwater contamination.

The yellowish color of water generally indicated the presence of iron $(\mathrm{Fe})$ in the collected water samples. The concentrations of iron in different locations of the study area were shown in Table 1 and Figure 4. The highest amount $(20.698 \mathrm{mg} / \mathrm{l})$ of iron was found in Maizbari while the lowest amount $(4.483 \mathrm{mg} / \mathrm{l})$ was found in Polosia of Tangail district, Bangladesh. It is found from the study that all of the samples were exceeded the standard levels of iron of World Health Organization (WHO) and Bangladesh standard which indicated that the sources of water are not suitable for drinking and uses for other purposes. The standard level of iron in Bangladesh was ranged from 0.30 to $1.00 \mathrm{mg} / \mathrm{l}$ (Table 1). Bangladesh Standard and Testing Institute (BSTI) and Indian standard level of iron is $1.00 \mathrm{mg} / \mathrm{l}$, while WHO standard level is 0.3 $\mathrm{mg} / \mathrm{l}$. According to WHO standard, the range of 20 to 60 times higher iron concentration reported than permissible limits in study area tube-well water. These higher amounts of iron found in the study area might be harmful to the member of those families who are using these water sources for their daily drinking and domestic purposes. Thus, the inhabitants of the study area should not drink these higher amounts of iron containing groundwater to overcome this problem, and should also find other sources or replace the tube-well or treat the water for drinking and other domestic and household purposes. In Bangladesh, groundwater withdrawals are causing a large iron contamination in groundwater levels during the dry season [20]. As millions of people of Bangladesh rely on groundwater sources for their daily domestic and other purposes, the assessment of groundwater quality is one of the most important tasks. The results of such investigations can minimize different health related problems and can ensure a healthy life with safe drinking water sources.

\subsection{Average Daily Intake Dose (ADD) of Arsenic}

The Agency for Toxic Substances and Disease Registry in 2000 demonstrated that arsenic can enter the human body via several pathways, but all other intake routes of arsenic are usually negligible in comparison to oral intake 
[24]. Thus, the average daily dose (ADD) of arsenic through drinking water (groundwater) was calculated to assess the arsenic intake at different levels. Analysis of drinking water from understudied As-exposed areas showed that the studied people subjects are continuously exposed to arsenic contaminated drinking water throughout their lives. The mean concentration of arsenic in drinking water can be used to calculate ADD by multiplying arsenic concentration of drinking water by daily intake volume. Daily individual water consumption is definitely influenced by other factors, for example, weather (air temperature and humidity) and labor intensity, in addition to body size of subjects. The intake rate (IR) might be 2-31 (average $2.5 \mathrm{l}$ ) per day. Whereas in the other parameters, exposure frequency (EF) based on 365 days/year, average exposure duration (ED) of 5.04 years, mean value of body weight (BW) of $60 \mathrm{~kg}$ for adult and $20 \mathrm{~kg}$ for children, and mean lifetime of 12,705 days were used for the calculation of ADD [25]. Taking into account only arsenic from water, intake by the community of understudied areas from underground water exceeded the recommended dose of WHO (Table 2) [26].

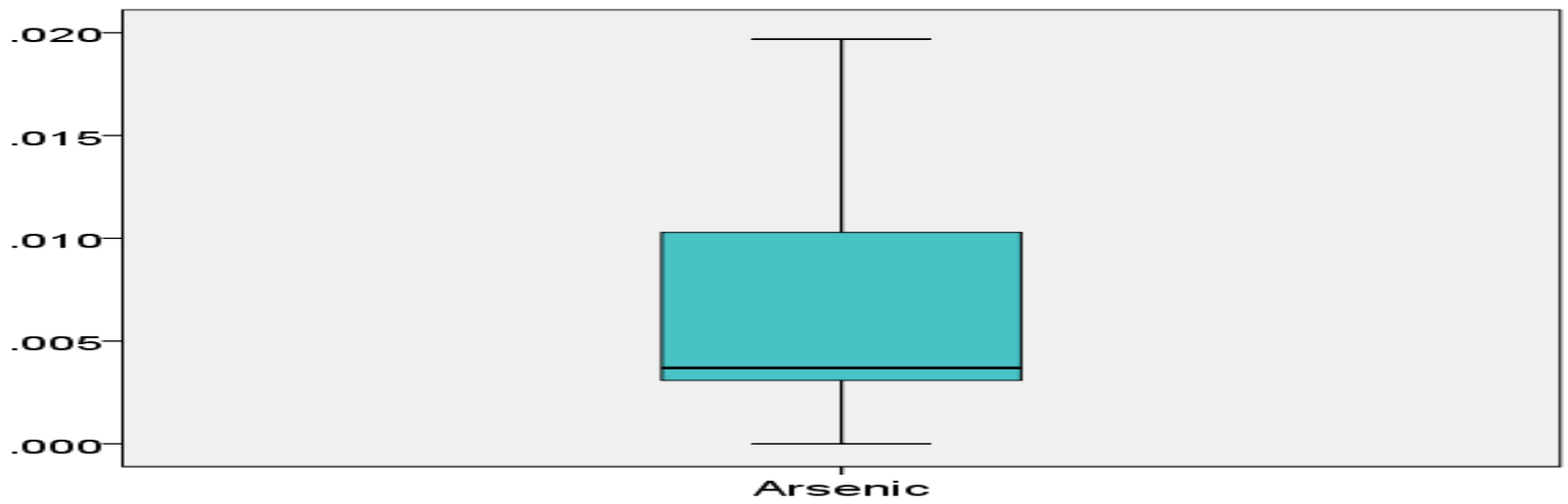

Figure 3. Arsenic concentration (mg/l) of tube-well water collected from Tangail district, Bangladesh

Table 1. Tube-well water sampling location with pH, EC (dS/m), Arsenic (mg/l), and Iron (mg/l) concentrations of tube-well water collected from Tangail district, Bangladesh

\begin{tabular}{|c|c|c|c|c|c|c|c|c|}
\hline Sample no. & Location & Latitude & Longitude & Altitude (m) & $\mathrm{pH}$ & $\mathrm{EC}(\mathrm{dS} / \mathrm{m})$ & Arsenic (mg/l) & $\operatorname{Iron}(\mathrm{mg} / \mathrm{l})$ \\
\hline 01 & Maizbari & 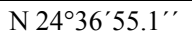 & E $89^{\circ} 55^{\prime} 1.7^{\prime \prime}$ & 20 & 6.71 & 0.32 & 0.01969 & 10.395 \\
\hline 02 & Maizbari & 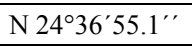 & E $89^{\circ} 55^{\prime} 1.8^{\prime \prime}$ & 20 & 6.88 & 0.15 & 0.00857 & 11.788 \\
\hline 03 & Maizbari & 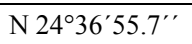 & E $89^{\circ} 55^{\prime} 2.1^{\prime \prime}$ & 19 & 6.54 & 0.22 & 0.01601 & 17.997 \\
\hline 04 & Maizbari & $\mathrm{N} 24^{\circ} 36^{\prime} 54.3^{\prime \prime}$ & E $89^{\circ} 55^{\prime} 2.0^{\prime \prime}$ & 19 & 6.89 & 0.18 & 0.00220 & 20.698 \\
\hline 05 & Maizbari & $\mathrm{N} 24^{\circ} 36^{\prime} 53.0^{\prime \prime}$ & E $89^{\circ} 55^{\prime} 2.1^{\prime \prime}$ & 19 & 6.96 & 0.25 & 0.00369 & 10.176 \\
\hline 06 & Maizbari & $\mathrm{N} 24^{\circ} 36^{\prime} 53.0^{\prime \prime}$ & $\mathrm{E} 89^{\circ} 55^{\prime} 0.9^{\prime \prime}$ & 18 & 6.71 & 0.23 & $<0.001$ & 15.571 \\
\hline 07 & Maizbari & 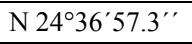 & E 895 $54^{\prime} 59.4^{\prime \prime}$ & 15 & 6.66 & 0.16 & 0.012 & 17.324 \\
\hline 08 & Maizbari & 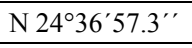 & E $89^{\circ} 54^{\prime} 58.9^{\prime \prime}$ & 15 & 6.65 & 0.15 & 0.00342 & 12.453 \\
\hline 09 & Maizbari & $\mathrm{N} 24^{\circ} 36^{\prime} 58.9^{\prime \prime}$ & E $89^{\circ} 54^{\prime} 55.8^{\prime \prime}$ & 17 & 6.98 & 0.11 & 0.00523 & 9.213 \\
\hline 10 & Polosia & $\mathrm{N} 24^{\circ} 36^{\prime} 56.0^{\prime \prime}$ & E $89^{\circ} 55^{\prime} 3.3^{\prime \prime}$ & 16 & 6.95 & 0.31 & 0.01708 & 13.269 \\
\hline 11 & Polosia & N 243ㅇㅎ․ $58.9^{\prime \prime}$ & E $89^{\circ} 54^{\prime} 56.2^{\prime \prime}$ & 16 & 6.61 & 0.16 & 0.00417 & 13.451 \\
\hline 12 & Polosia & $\mathrm{N} 24^{\circ} 36^{\prime} 59.0^{\prime \prime}$ & E $89^{\circ} 55^{\prime} 3.2^{\prime \prime}$ & 17 & 6.67 & 0.21 & 0.00275 & 7.984 \\
\hline 13 & Polosia & $\mathrm{N} \mathrm{24^{ \circ } 3 7 ^ { \prime } 0 . 9 ^ { \prime \prime }}$ & E $89^{\circ} 55^{\prime} 4.2^{\prime \prime}$ & 17 & 6.88 & 0.59 & 0.00362 & 4.483 \\
\hline 14 & Polosia & 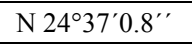 & E $89^{\circ} 55^{\prime} 3.2^{\prime \prime}$ & 21 & 6.91 & 0.21 & 0.00218 & 15.418 \\
\hline 15 & Simla & $\mathrm{N} 24^{\circ} 36^{\prime} 50.0^{\prime \prime}$ & E $89^{\circ} 55^{\prime} 6.0^{\prime \prime}$ & 14 & 6.83 & 0.31 & 0.00344 & 17.286 \\
\hline \multicolumn{7}{|c|}{ Level on Quantization (LoQ) } & 0.001 & 0.1 \\
\hline \multicolumn{7}{|c|}{ Bangladesh Drinking Standard (BDS) } & 0.05 & $0.3-1$ \\
\hline
\end{tabular}

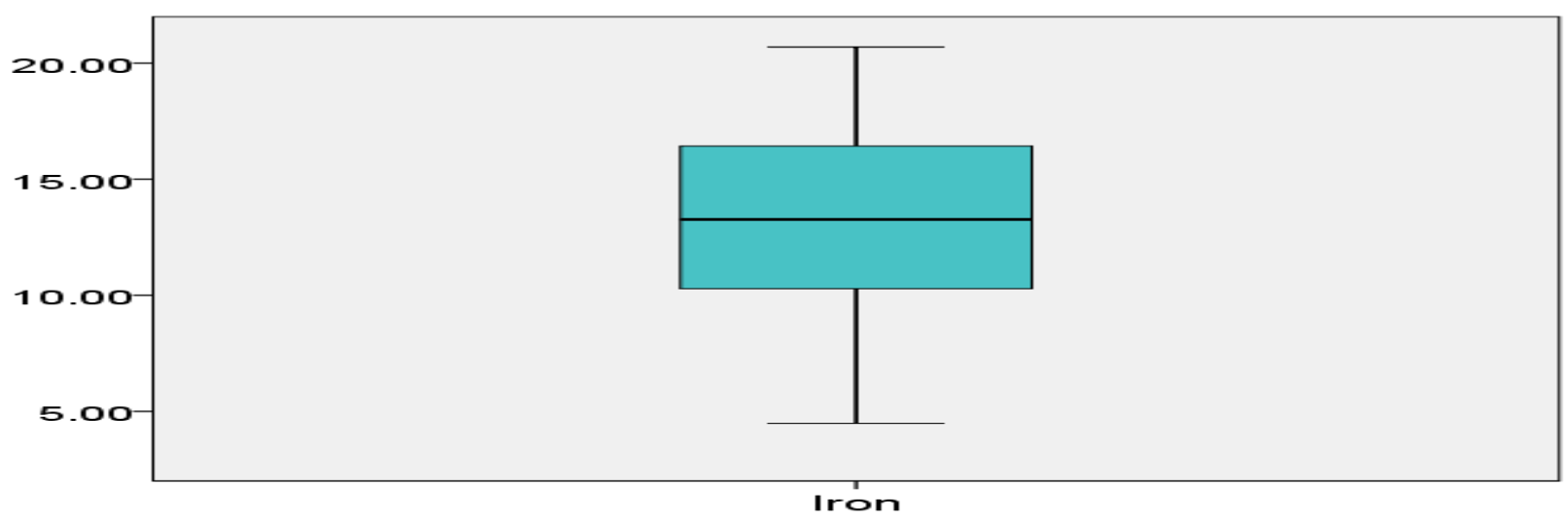

Figure 4. Iron concentration (mg/l) of tube-well water collected from Tangail district, Bangladesh 
Table 2. Estimated average daily intake dose (ADD) of arsenic (mg/l/day) due to drinking of tube-well water for both adult and children in Tangail district, Bangladesh

\begin{tabular}{|c|c|c|}
\hline Sample no. & \multicolumn{2}{|c|}{ Arsenic (mg///day) } \\
\hline & Adult & Children \\
\hline 01 & 0.000985 & 0.005198 \\
\hline 02 & 0.000429 & 0.005894 \\
\hline 03 & 0.000801 & 0.008999 \\
\hline 04 & 0.00011 & 0.000349 \\
\hline 05 & 0.000185 & 0.005088 \\
\hline 06 & 0.00005 & 0.007786 \\
\hline 07 & 0.0006 & 0.008662 \\
\hline 08 & 0.000171 & 0.006227 \\
\hline 09 & 0.000262 & 0.004607 \\
\hline 10 & 0.000854 & 0.006635 \\
\hline 11 & 0.000209 & 0.006726 \\
\hline 12 & 0.000138 & 0.003992 \\
\hline 13 & 0.000181 & 0.002242 \\
\hline 14 & 0.000109 & 0.007709 \\
\hline 15 & 0.000172 & 0.008643 \\
\hline
\end{tabular}

\subsection{Hazard Quotient (HQ) and Carcinogenic Risk Assessment (R)}

The HQ and R values were calculated on the bases of ADD values as shown in Table 3. The methodology for the estimation of non-carcinogenic risks was applied in accordance with that provided by the U.S. Environmental Protection Agency (USEPA) Region III's risk-based concentration table. The non-carcinogenic risk for each individual metal through tube-well water drinking were assessed by the target hazard quotient (THQ), which is "the ratio of a single substance exposure level over a specified time period (e.g., sub-chronic) to a reference dose (RfD) for that substance derived from a similar exposure period". Risk assessment is the process that evaluates the potential health effects from doses to humans of arsenic contaminant received through exposure pathway. The non-carcinogenic risks from drinking of tube-well water by the adult inhabitants and children were assessed based on the hazard quotients (HQ). The noncarcinogenic risk for adult and children were 0.358 to 3.238 and 1.148 to 29.6 respectively. On the bases of these findings, both adult and children are at risk of chronic toxicity of arsenic, which was indicated by HQ values $>1$. Corresponding to these results, the first cases of arsenicosis were reported in Gambat sub-district during 2002-2003, Sindh Province, India, along with Indus River [26].

The carcinogenic risks of arsenic from drinking of tubewell water by the adult and children inhabitants were assessed based on the target carcinogenic risk (R). Cancer risk due to drinking tube-well water shown in Table 3 . The findings of this study indicated that drinking tube-well water in the studied area surely poses cancer risk to the people who drink those tube-well water. It was reported in the literature that the increased prevalence of skin diseases has been observed even at the exposure levels in the range of 5-10 $\mu \mathrm{g} / 1$ arsenic in drinking waters [27]. Skin cancers, internal cancers (Bladder, Kidney, and Lung) were reported due to arsenic contamination in tube-well water. In Taiwan, populations exposed to high concentrations of arsenic in their drinking water, containing an average of $800 \mathrm{mg} / \mathrm{l}$ of arsenic, had estimates of their relative risk of bladder cancer in the order of 30-60 [28]. In Argentina, a mortality study in the arsenic-exposed region of Co'rdoba found increased risks of bladder and lung cancer among men and women from 1986 to 1991, although concentrations were lower (average 178 $\mathrm{mg} / \mathrm{l}$ ) than in Taiwan and Chile [29]. Using the current US Environmental Protection Agency standard of $50 \mathrm{mg} / \mathrm{l}$, it has been estimated that the lifetime risk of dying from cancer of the liver, lung, kidney or bladder while drinking 1 liter a day of water containing arsenic at this concentration could be as high as 13 per 1000 persons exposed [30].

Table 3. Estimated hazard quotient (HQ) and carcinogenic risk factor (R) of arsenic and iron from tube-well water for both adult and children in Tangail district, Bangladesh

\begin{tabular}{|c|c|c|c|c|}
\hline Sample no. & \multicolumn{2}{|c|}{ Hazard quotient (HQ) } & \multicolumn{2}{c|}{ Carcinogenic risk factor (R) } \\
\hline & Adult & Children & Adult & Children \\
\hline 01 & 3.238487 & 17.09704 & 0.001476 & 0.007767 \\
\hline 02 & 1.409539 & 19.38816 & 0.000643 & 0.008802 \\
\hline 03 & 2.633224 & 29.60033 & 0.001201 & 0.013408 \\
\hline 04 & 0.361842 & 1.148026 & 0.000165 & 0.000523 \\
\hline 05 & 0.606908 & 16.73684 & 0.000277 & 0.007603 \\
\hline 06 & 0.164474 & 25.6102 & $7.5 \mathrm{E}-05$ & 0.011611 \\
\hline 07 & 1.973684 & 28.49342 & 0.0009 & 0.012909 \\
\hline 08 & 0.5625 & 20.48191 & 0.000256 & 0.009297 \\
\hline 09 & 0.860197 & 15.15296 & 0.000393 & 0.006887 \\
\hline 10 & 2.809211 & 21.82401 & 0.00128 & 0.009903 \\
\hline 11 & 0.685855 & 22.12336 & 0.000313 & 0.010038 \\
\hline 12 & 0.452303 & 13.13158 & 0.000207 & 0.00597 \\
\hline 13 & 0.595395 & 7.373355 & 0.000271 & 0.003357 \\
\hline 14 & 0.358553 & 25.35855 & 0.000163 & 0.011497 \\
\hline 15 & 0.565789 & 28.43092 & 0.000258 & 0.012881 \\
\hline
\end{tabular}

\section{Conclusions}

The evaluations of arsenic and iron contents in tubewell groundwater of Tangail district, Bangladesh were performed in order to be aware of the arsenic and iron pollution in the study area. It is concluded that arsenic concentration in most of the tube-well water and 100\% iron in tube-well water was higher than the permissible limits proposed by WHO. The findings of this study indicate that drinking tube-well water in the studied area surely poses the cancer risk to the people who drink those tube-well water. To reduce the impact of arsenic on human health there is an urgent need to develop treatment systems to remove arsenic from drinking water. These higher amounts of iron found in the studied vicinity may be harmful to the studied area inhabitants who drink those tube-well water. People should be aware of the drinking pure water and they may search another alternative source of pure drinking water.

\section{Acknowledgements}

The authors thank the authority of Patuakhali Science and Technology University (PSTU), Bangladesh and Department 
of Public Health Engineering (DPHE), Bangladesh for providing laboratory facilities to complete this study.

\section{References}

[1] Azad, A.K., "Impacts of Farakka Barrage on surface water resources in Bangladesh, World Environment Day, Report of Department of Environment, Government of the People's Republic of Bangladesh". pp: 40-43. 2003.

[2] Gunatilaka, A., "Groundwater woes of Asia". Asian Water, January/February count. 2005.

[3] Talukder, S.A., Chatterjee, A., Zheng, J., Kosmus, W., "Studies of Drinking Water Quality and Arsenic Calamity in Groundwater of Bangladesh". Proceedings of the International Conference on Arsenic Pollution of Groundwater in Bangladesh: Causes, Effects and Remedies, Dhaka, Bangladesh. 1998.

[4] Ahmad, M.A., Kahlown, A., Tahir, H., Rashid., "Arsenic an Emerging Issue, Experiences from Pakistan". 30th WEDC International Conference, Vientiane, Lao PDR. 2004.

[5] Baig, J.A., Kazi, T.G., Shah, A.Q., Afridi, H.I., Nida, S.K., Kolachi, F., Kandhro, G., "Evaluation of Toxic Risk Assessment of Arsenic in Male Subjects Through Drinking Water in Southern Sindh Pakistan". 2009.

[6] Anonymous., "Water: A millennial priority". The Acme Agrovat and Beverage Ltd., Dhaka, Bangladesh. 2004.

[7] Luo, W., Lu, Y., Giesy, J.P., Wang, T., Shi, Y., "Effects of land use on concentrations of metals in surface soils and ecological risk around Guanting Reservoir, China". Environmental Geochemistry and Health, 29: 459-471. 2007.

[8] WHO., "Arsenic compounds Environmental Health Criteria". 2nd ed. World Health Organization, Geneva. 2001.

[9] Rukshana, F., Haque, M.N., Mazumder, M.H., Chowdhury, S.R., Ahmed, G.U., Quadir, M.E., "Arsenic investigation of drinking water in some area of Faridpur district". Tech. Journal, 9. 99-107. 2002.

[10] WARPO (Water Resource Planning Organization)., "Main report, v.2, National Water Management Plan Project". Ministry of Water Resource, Government of the People's Republic of Bangladesh. 2000.

[11] Finkelman, R.B., Orem, W., "Health Impacts of Coal and Coal use: Possible solutions". International Journal of Coal Geology, 50. 425-443. 2002.

[12] Mandal, B.K., Suzuki, K.T., "Arsenic round the world: a review, Talanta". 58. 201-235. 2002.

[13] Khan, A.W., "Arsenic contamination in groundwater and its effect on human health with particular reference to Bangladesh". Journal of Preventive and Social Medicine, 16. 65-73. 1997.
[14] WHO., "guidelines for drinking-water quality". Vol 2, 2nd ed. Geneva, World Health Organization. 1996.

[15] United Nations Children's Fund (UNICEF)., "Arsenic mitigation in Bangladesh". (Internet communication, 14 December 1999, available at http://www.unicef.org/arsenic). 1999.

[16] Daily Star Report., "8500 Arsenic Patients Detected in Country". The Daily Star, A national daily newspaper of Bangladesh, 11 September. 2000.

[17] Elinder, C.G., "Handbook on the technology of metals". V. 2, Amsterdam, Elsevier, pp: 276-297. 1986.

[18] Bader, J.S., "Ground-water contamination, The United State of America and Puerto Rica, U. S. Geological Survey, Washington DC, USA". pp: 103. 1973.

[19] Meyer, C.F., "Polluted ground: Some causes, effects, controls, and monitoring". Rept. EPA-600/4-73-0016, U. S. Environmental Protection Agency, Washington DC, USA, pp: 282. 1973.

[20] Ahmed, M.F., Rahman, M.M., "Water supply and sanitation, Specific groundwater treatment process". Centre for water supply and waste management, BUET, Dhaka, Bangladesh. Section 19.3, pp: 371-405. 2000.

[21] APHA (American Public Health Association)., "Standard methods for the examination of water and wastewater". 19th edn. American Public Health Association, Washington DC, USA. 1998.

[22] USEPA., "Integrated risk information system: arsenic, inorganic. CASRN". 7440-38-2. 1998.

[23] USEPA., "Risk-based Concentration Table US Environmental Protection Agency Washington, DC/Philadelphia, PA”. 2000.

[24] Moschandreas, D.J., Karuchit, S., Berry, M.R., O’Rourke, M.K., "Exposure apportionment: ranking food items by their contribution to dietary exposure". Journal of Exposure Analysis and Environmental Epidemiology, 12. 233-243. 2002.

[25] ATSDR., "Toxicology profile for arsenic. Atlanta, Georgia, Agency for Toxic Substances and Disease Registry, US Department of Health and Human Services". TP-92/02. 2000.

[26] WHO., "Guidelines for drinking-water quality". 3rd ed. WHO, Geneva PCRWR (2002-2003) (Pakistan Council of Research in Water Resources). Arsenic and health effects. 2004.

[27] Yoshida, T., Yamauchi, H., Fan, S.G., "Chronic health effects in people exposed to arsenic via the drinking water: dose-response relationships in review". Toxicology and Applied Pharmacology, 198. 243-252. 2004.

[28] Chen, C.J., Chen, C.W., Wu, M.M., "Arsenic and cancer". Lancet, 1. 414-415. 1988.

[29] Hopenhayn-Rich, C., Biggs, M.L., Smith, A.H., "Lung and kidney cancer mortality associated with arsenic in drinking water in Cordoba, Argentina". International Journal of Epidemiology, 27. 561-569. 1998.

[30] Smith, A.H., "Cancer risks from arsenic in drinking water". Environmental Health Perspectives, 97. 259-257. 1992. 